\title{
Starch Granule Size and Morphology as a Proxy for Water Regime Influence on Zea mays
}

\author{
Stefania Wilks ${ }^{1}$, Lisbeth A. Louderback ${ }^{1 *}$, and Shannon Boomgarden ${ }^{2}$ \\ ${ }^{1}$ Department of Anthropology, Natural History Museum of Utah, University of Utah, Salt Lake City, USA. ${ }^{2}$ Natural History \\ Museum of Utah, Director, Range Creek Field Station, Department of Anthropology, University of Utah, Salt Lake, USA. \\ *Ilouderback@anthro.utah.edu
}

\begin{abstract}
A wealth of information on the patterns of human subsistence and plant domestication has been generated from studies on maize (Zea mays) starch granules. However, very little work has been conducted on how the size and morphology of those granules might change as a function of water stress during the growing season. In the arid Southwest, the role of irrigation in growing maize is an essential parameter in many foraging models. Our study seeks to determine if there are significant changes in the size and other morphological attributes of starch granules from maize planted at Range Creek Canyon under two different irrigation regimes ranging from little water (once every three weeks) to ample water (once a day). Our results provide data on the effects of irrigation on Z. mays starch granules and, therefore, have implications for identifying archaeological maize and possibly determining past water regimes at Range Creek Canyon.
\end{abstract}

Received August 14, 2020

OPENӘACCESS

Accepted December 22, 2020

DOI 10.14237/ebl.12.1.2021.1725

Published March 15, 2021

Keywords Agriculture, Arid western North America, Irrigation, Fremont culture, Starch analysis, Maize

Copyright @ 2021 by the author(s); licensee Society of Ethnobiology. This is an open-access article distributed under the terms of the Creative Commons Attribution-NonCommercial 4.0 International Public License (https://creativecommons.org/licenses/by-nc/4.0), which permits non-commercial use, distribution, and reproduction in any medium, provided the original author and source are credited.

\section{Introduction}

Starch is an energetically important polymer of glucose produced as a by-product of photosynthesis. It is preserved inside a plant's amyloplasts as discrete granules. Size and other morphological attributes of the granules differ depending on plant species and are important identifying features (Bertoft 2017; Jane et al. 1994). Starchy plant foods such as cereal grains like maize, as well as roots, rhizomes, and tubers, were considered important in human evolution (Messner et al. 2008; Wells et al. 2020; Wrangham et al. 1999). Furthermore, global patterns of human subsistence and plant domestication have been generated from several studies on maize starch granules found on artifacts or in sediments (Holst et al. 2007; Musaubach et al. 2013; Piperno et al. 2009; Yang and Perry 2013; Zarillo et al. 2008).

In the arid Southwest, the role of irrigation in growing maize is an important parameter in many foraging models (Mabry 2005). Uncertainties in rainfall patterns require situational adaptation and increased resiliency in maize agriculture systems (Adams et al. 2006; Werth 2007). Under such circumstances, it is important that agricultural practices improve the efficient use of limited resources and ensure substantial productivity gains. For farmers, the number of crops harvested is the benefit of farming, and the effort expended in obtaining that harvest determines the cost. All else equal, evidence of water stress means lower rates of return for farming. This has implications concerning the trade-off between hunting and gathering wild resources and effort expended on other field activities related to farming.

For maize, the effective management of water produced with irrigation is a major predictor of increased kernel number and size (Adams 2015; Benson et al. 2013; Boomgarden et al. 2019). Physiological response to water stress in maize is measured in a multitude of ways, including total biomass yield, reduction in leaf area, increases in rootshoot ratio, reduced number of ears, kernels per ear, 


\section{Data, Methods \& Taxonomies}

and kernel size. Furthermore, significant relationships between drought, reduced maize yield, and kernel size are well documented (Benson et al. 2013; Boomgarden et al. 2019; Muenchrath 1995; Shaw 1988). Very little work, however, has been conducted on how the size and morphology of starch granules stored in those kernels might change as a function of water stress during the growing season. Our study seeks to determine if there are significant changes in the size or morphology of starch granules from maize planted at the Range Creek Field Station under two different irrigation regimes: very little water (once every three weeks) to ample water (once a day). This study has implications for identifying archaeological maize and possibly determining past farming investment strategies.

\section{Range Creek Canyon and Experimental Maize Irrigation Farming}

The Range Creek Field Station is located within the Book Cliffs, along the Tavaputs Plateau, 40 miles southeast of Price, Utah (Figure 1). Human populations of the Fremont culture flourished in the canyon from 1100-700 cal yrs BP. They were huntergatherers who also farmed maize and stored numerous cobs in granaries tucked in sandstone cliffs throughout the canyon (Boomgarden et al. 2014; Coltrain 2011; Metcalfe 2008; Towner et al. 2009). The goal of the field station is to examine adaptations of arid-land foragers and farmers through paleoenvironmental, experimental, and archaeological lines of evidence (Boomgarden 2015; Boomgarden et al. 2014, 2019). Since little is known about the farming techniques used by the Fremont, experiments conducted at the field station examine the economic trade-offs related to dry versus irrigation farming documented archaeologically and ethnographically throughout the Southwest (Arbolino 2001; Ingram and Hunt 2015; Mabry 2005; Nabhan 1983).

Irrigation farming requires modifications and investments in surface features that will move or control incoming water. Construction and management of features designed to move, direct, or control intermittent or permanent surface water can be costly (Simms et al. 2020). Ethnographically, the costs associated with these techniques vary from minimal to intensive through the combination of various strategies (Arbolino 2001; Doolittle 1984; Mabry 2005). For example, minimal investments in irrigation may include branches placed in a shallow, intermittent drainage to spread the occasional surface

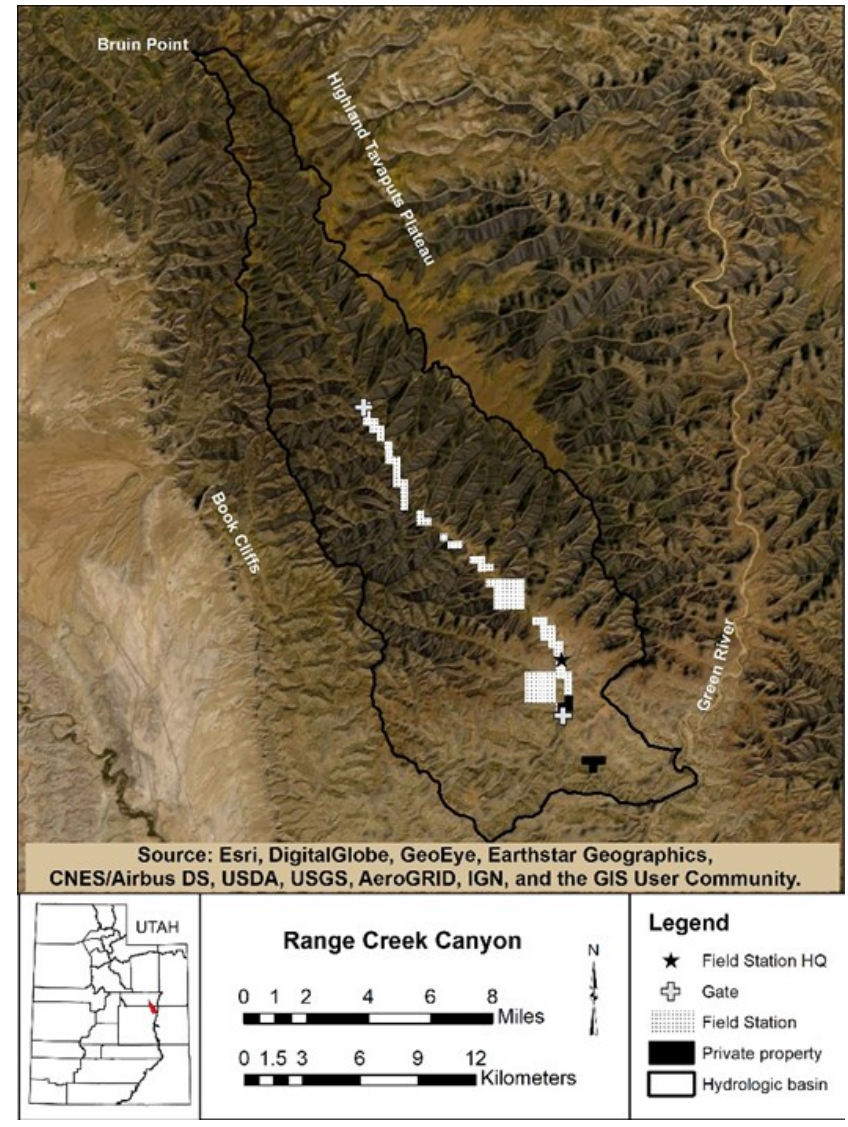

Figure 1 Range Creek Canyon (575040 E, $4356861 \mathrm{~N}$ ) is located in the Book Cliffs along the Tavaputs Plateau, 40 miles southeast of Price, Utah.

water from storms, whereas high investment could include terracing hillsides or building massive canal systems to move water from rivers to distant fields (Arbolino 2001; Benson 2010; Castetter and Bell 1942; Doolittle 1984; Mabry 2005; Nabhan 1983; Rhode 1995; Simms et al. 2020). Permanent sources of water, like the creek in Range Creek Canyon, offer a relatively low risk strategy with respect to minimizing water stress in crops, whereas irrigation techniques that rely on capturing rainfall are dependent on the frequency and duration of precipitation occurring in the right location. The irrigation experiments at Range Creek replicate the simple surface diversion techniques documented at several Fremont sites in Utah (Metcalfe and Larrabee 1985; Talbot and Richens 1996) and are particularly focused on measuring the costs (labor) and benefits (maize yield) of simple irrigation farming (Boomgarden et al. 2019). These experiments documented the differences in maize yield (the number of cobs and the number and 

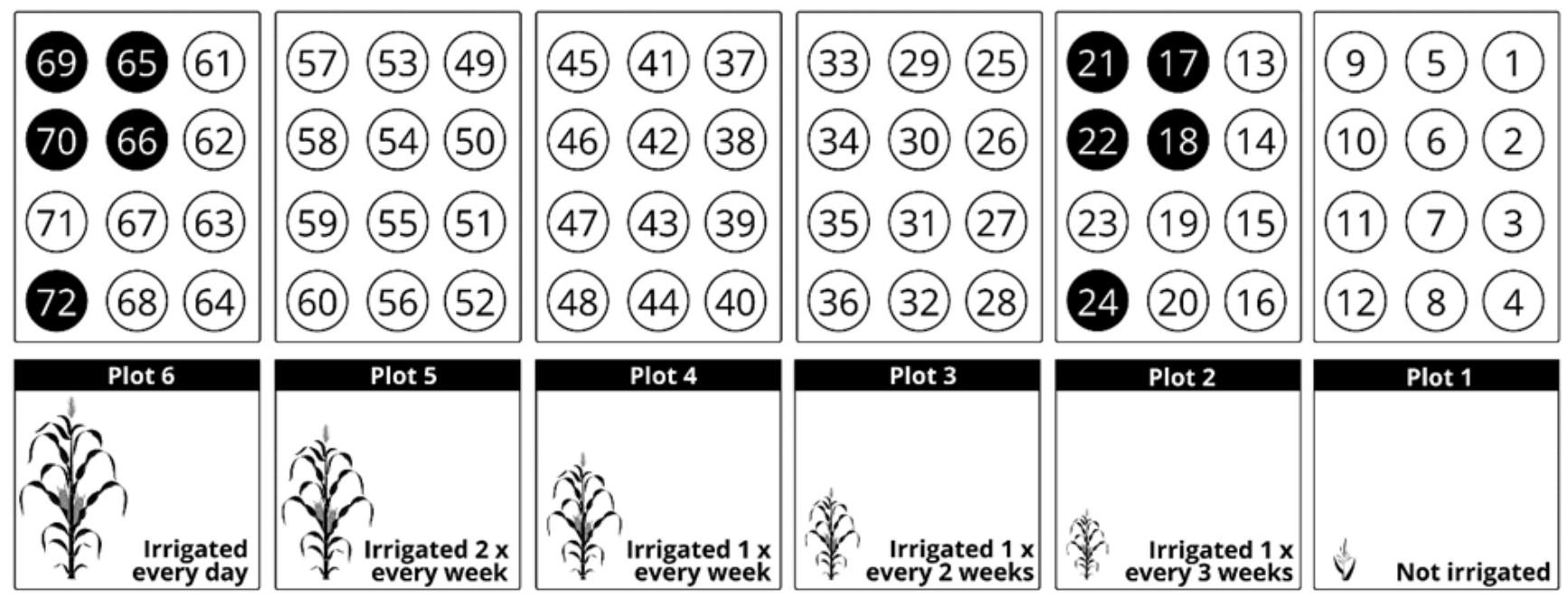

Figure 2 Experimental maize farming at Range Creek Field Station. Six plots of Tohono O'odham 60-day maize with different watering schedules were planted, each with 12 growing basins. Five replicate samples (solid circles) of maize kernels from Plots 2 and 6 were sampled for this study.

size of kernels on each cob) as a function of water stress resulting from differing amounts of irrigation water (Boomgarden 2015).

The maize chosen for the experiment was an heirloom variety of Tohono O'odham 60 day because of its short growing season compared to other Native American maize landraces (Adams et al. 1999; Adams et al. 2006; Muenchrath 1995). Adams and colleagues (2006) describe the variability in maize landraces grown historically by measuring maize ear characteristics and kernel traits, temperature parameters, and grain yield estimates from a two year grow out (2004-2005) in Farmington, New Mexico. The project recorded emergence and maturity dates on 86 of the 123 accessions analyzed. The mean number of days from emergence to maturity for all 86 maize accessions from all three culture regions/ groups was 128 days (e.g., Adams et al. 2006:Table 15). It is clear that based on the frost-free growing season in Range Creek Canyon, many varieties of Native American maize can be grown in the lower reaches of the canyon. Six plots of Tohono O'odham 60-day maize with different watering schedules were planted in the Range Creek experiment, each with 12 growing basins containing four seeds. For the purposes of this study, maize kernels were selected from Plot 2 (watered once every three weeks) and Plot 6 (watered every day). Plot 1 (which was not irrigated) did not produce sufficient maize cobs or kernels for analysis (Figure 2).

\section{Methods \\ Starch Granule Analysis}

Five replicate samples of maize kernels from the two most extreme watering treatments (Plot 2 and Plot 6) were processed in the Archaeobotanical Lab at the Natural History Museum of Utah. Starch granules were examined for their size and morphological attributes to quantify differences between water treatments.

\section{Starch Extraction}

Only mature endosperm from the maize kernels was selected. To extract the starch granules, a dried kernel was cut in half with a sterile razor blade, removing the endosperm from its outer pericarp hull (Holst et al. 2007; Musaubach et al. 2013). The collected endosperm (containing starch granules) was then transferred to a sterile mortar and lightly ground to a fine flour. The flour was sieved through a $125 \mu \mathrm{m}$ mesh Endecott screen into a beaker using DH20. Sample material $<125 \mu \mathrm{m}$ was transferred to a sterile $50 \mathrm{ml}$ test tube and each sample was centrifuged for three minutes at $3000 \mathrm{RPM}$. The supernatant was discarded, and the sample pellet was transferred to a sterile $15 \mathrm{ml}$ test tube. Each test tube was resuspended with a vortex mixer, adding $7 \mathrm{ml}$ of lithium heteropolytungstate (LST; specific gravity 2.00), and then centrifuged for 15 minutes at 1000 RPM. The sample was extracted from the heavy liquid using a pipette, carefully removing the top 1-2 $\mathrm{mm}$ layer of 
Table 1 Descriptive statistics and Shapiro-Wilk normality test of starch granule lengths for replicate and pooled samples from Plots 2 and 6.

\begin{tabular}{llllllll}
\hline Samples & Sample Size (n) & Mean & SD & Median & Skewness & Kurtosis & Shapiro-Wilk \\
\hline Replicate Samples & & & & & & & \\
LS2.17 & 50 & 8.17 & 1.34 & 8.08 & 0.40 & -0.34 & $p=0.279$ \\
LS2.18 & 51 & 8.85 & 1.63 & 8.84 & 0.17 & -0.94 & $p=0.226$ \\
LS2.21 & 56 & 7.48 & 1.20 & 7.58 & 0.07 & 0.47 & $p=0.4347$ \\
LS2.22 & 102 & 12.45 & 2.07 & 12.38 & 0.23 & 0.04 & $p=0.9061$ \\
LS2.24 & 51 & 8.30 & 1.62 & 8.26 & -0.15 & -0.16 & $p=0.9716$ \\
LS6.65 & 51 & 8.91 & 1.33 & 8.87 & -0.30 & 0.21 & $p=0.6774$ \\
LS6.66 & 56 & 10.58 & 1.90 & 10.52 & 0.36 & -0.18 & $p=0.5172$ \\
LS6.69 & 52 & 9.78 & 1.50 & 9.64 & 0.56 & 0.88 & $p=0.2997$ \\
LS6.70* & 100 & 16.14 & 1.22 & 16.37 & 0.05 & 0.08 & $p=0.0296$ \\
LS6.72 & 51 & 8.49 & 1.62 & 8.13 & 0.65 & 0.32 & $p=0.0862$ \\
Pooled Samples & & & & & & & \\
Plot 2 & 5 & 9.05 & 1.96 & 8.3 & -- & -- & -- \\
Plot 6 & 5 & 10.78 & 3.10 & 9.78 & -- & -- & -- \\
\hline
\end{tabular}

*Measurements from sample LS6.70 were log-transformed because it had a non-normal distribution.

organics containing starch and placed into new $15 \mathrm{ml}$ test tubes. Each sample was rinsed three times until all residual heavy liquid was removed. Samples were then rinsed with acetone, mixed with a vortex, and centrifuged for 3 minutes at 3000 RPM. The acetone was decanted, and samples were covered and left to dry overnight. Once dried, the samples were mixed with 50\% DH20 and 50\% glycerol solution and then mounted on microscope slides.

\section{Starch Granule Size and Formal Attributes}

Slides were positioned using randomly chosen $\mathrm{X}-\mathrm{Y}$ coordinates. Each slide was scanned using a transmitted brightfield microscope fitted with polarizing filters and Nomarski optics (Zeiss Axioscope 2, Zeiss International, Göttingen, Germany) and all starch granules within that field of view were measured and photographed. Starch granules from each replicate treatment sample (Plots 2 and 6; five replicates from each plot) were measured and photographed, for a total of 310 granules in Plot 2 and 310 granules in Plot 6.

Maximum length measurement of starch granules was made using the Zeiss Zen measurement software (accuracy $=+/-0.001 \mu \mathrm{m})$. At the same time, several morphological attributes were documented, including hilum position $(0=$ eccentric and $1=$ centric $)$, shape $(0=$ not irregular, and $1=$ irregular $)$, and fissures $(0=$ no fissure, $1=$ stellate, $2=$ transverse, and $3=$ radial $)$. These attributes have been previously described (Holst et al. 2007; ICSN 2011; Reichert 1913;
Torrence and Barton 2016) and chosen based on studies that documented them in maize starch granules (Holst et al. 2007; Musaubach et al. 2013; Piperno et al. 2004, 2009).

Shapiro-Wilk normality tests were performed on all starch granule size distributions and reported as $\mathrm{p}$ values (Table 1). P-values higher than 0.05 indicate the distributions are normal. Pooled starch granule size distributions for Plots 2 and 6 were plotted using the strip chart function in the $\mathrm{R}$ Graphics Package ( $\mathrm{R}$ Core Team 2019) and compared using KolmogorovSmirnov (K-S) tests. We examine the size distributions and the frequencies of the different morphological features for all starch granule sizes $(100 \%)$ as well as the largest $20 \%$ of granules from each sample.

\section{Results}

Starch Granule Size and Formal Attributes

Starch granule lengths from the treatment samples (Plots 2 and 6; five replicates from each plot) exhibit normal distributions, except for LS6.70 which was subsequently log-transformed (Table 1). Treatment samples were then pooled for statistical comparisons. Relying on the upper $20 \%$ size range allows for greater differentiation between samples because it has been shown that different species can have different maximum granule sizes (Herzog et al. 2018; Liu et al. 2014; Louderback et al. 2016).

Starch granule size distributions $(100 \%$ and top $20 \%$ ) from Plots 2 and 6 are shown in Figure 3. Both 
distributions from each sample fraction are significantly different $(\mathrm{K}-\mathrm{S}$ test, $\mathrm{P}<0.0001)$ from each other. Furthermore, there is less overlap in granule sizes from Plots 2 and 6 within the top 20\% size range, making it easier to define a size range that can be used to characterize the irrigation plot (Figure 3).

Morphological attributes, including hilum position, two-dimensional granular profile, and fissure type were recorded for each granule in Plots 2 and 6 (Figure 3). These attributes occur more frequently in the upper $20 \%$ size range of starch granules and, therefore, we report statistics for those granules (Table 2).

\section{Plot 2}

Dominant features observed on the upper 20\% size range of starch granules from Plot 2 included irregular -shaped two-dimensional profile (0.97; Figure 3B, C) with centric hila $(0.77)$. Transverse fissures were most frequently observed (0.45; Figure $3 \mathrm{~B})$, while stellate and radial fissures were rarely observed $(0.08$ and 0.02, respectively; Figure 3B, C). The overall frequency of fissures observed on granules was approximately 0.55. The upper $20 \%$ size range in Plot 2 is $11.94-18.47 \mu \mathrm{m}$.

Plot 6

Dominant features observed on the upper $20 \%$ size of Plot 6 granules include irregular shaped granules (0.90; Figure 3a, b) with centric hila (0.51). Transverse fissures were also the most commonly observed fissure type (0.46; Figure $3 \mathrm{a})$, while stellate and radial were less frequent $(0.24$ and 0.03 , respectively; Figures $3 \mathrm{a}, \mathrm{b})$. The overall frequency of fissures observed on granules in Plot $6(\Sigma=0.73)$ is much higher than in Plot $2(\Sigma=0.55)$, most likely due to the increased size of the starch granules. The upper $20 \%$ size range of Plot 6 is $15.36-28.16 \mu \mathrm{m}$.

\section{Discussion}

This study demonstrates that the size of maize starch granules reflects the amount of moisture the parent plant receives and, therefore, is a function of water stress during a growing season. Size distributions from high-water Plot 6 are significantly skewed towards larger granules when compared to distributions from low-water Plot 2. Size differences are especially apparent within the upper $20 \%$ size category and,

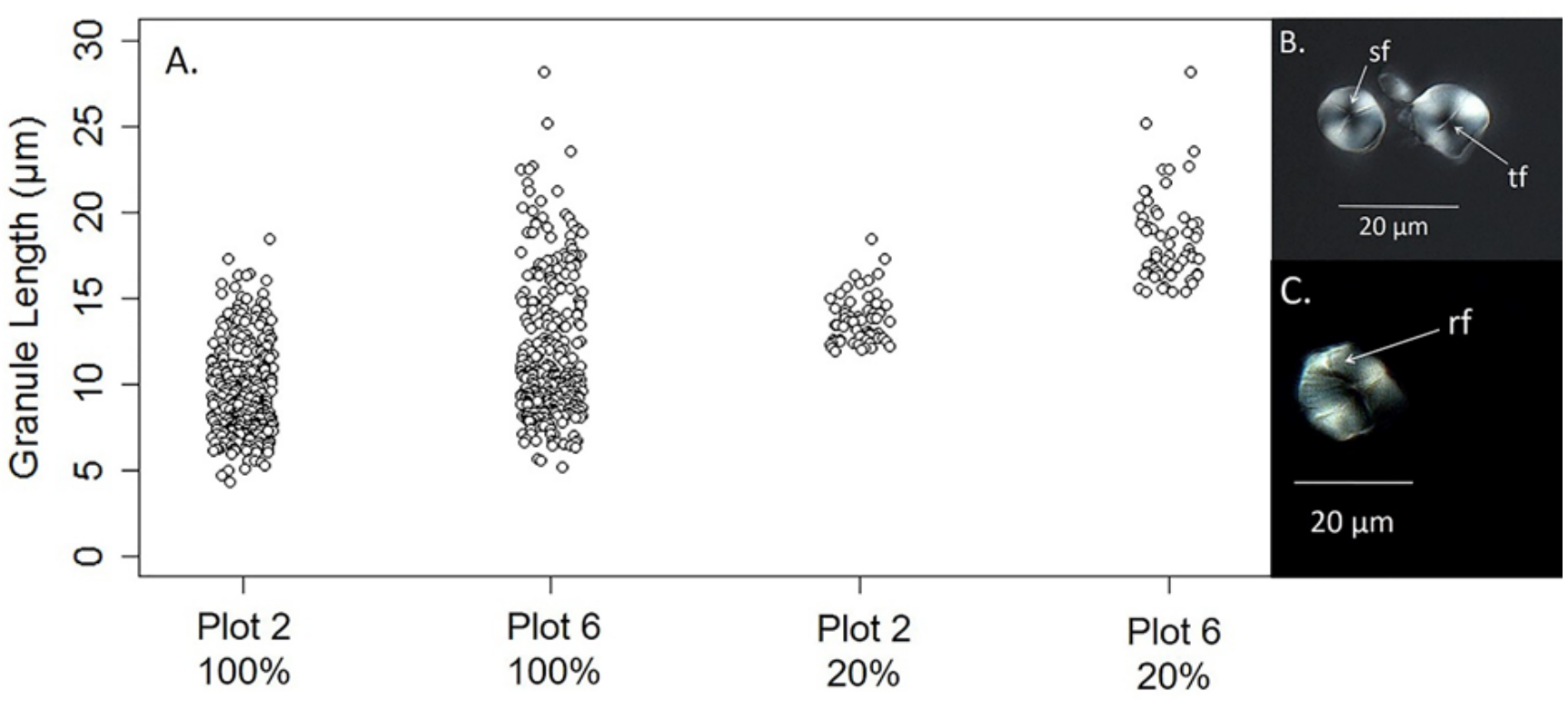

Figure 3 A Starch granule size distributions of pooled samples $(100 \%)$ from Plot $2(n=310)$ and Plot $6(n=310)$. Size distributions for the upper $20 \%$, both plots $(n=62)$. Comparisons between distributions from each sample fraction were significantly different $(p<0.0001)$. (Right) Morphological attributes (Nomarski optics, DIC) include $\mathbf{B}$ sf = three-armed stellate fissure radiating from the hilum on an irregular granule from Plot $6, \mathrm{tf}=$ transverse fissure dissecting the hilum and extending toward the margin of an irregular-shaped granule from Plot 6 and $\mathbf{C}$ rf = radial fissure radiating from the hilum to the margin of an irregular-shaped granule from Plot 6. 
Table 2 Frequencies of morphological features and size range of starch granules from the upper $20 \%$ pooled samples.

\begin{tabular}{lllllll}
\hline & & \multicolumn{3}{c}{ Fissures } \\
\cline { 3 - 5 } Samples & Hilum Position & Shape & Stellate & Transverse & Radial & Granule size range \\
\hline Plot $2(\mathrm{n}=62)$ & Centric: 0.77 & $\begin{array}{l}\text { Irregular: } 0.97 \\
\text { Other: } 0.03\end{array}$ & 0.08 & 0.45 & 0.02 & $11.94-18.47 \mu \mathrm{m}$ \\
Plot $6(\mathrm{n}=62)$ & Centric: 0.51 & $\begin{array}{l}\text { Irregular: } 0.90 \\
\text { Other: } 0.10\end{array}$ & 0.24 & 0.46 & 0.03 & $15.36-28.16 \mu \mathrm{m}$ \\
\hline
\end{tabular}

therefore, could be useful when determining ancient watering regimes from archaeological materials (i.e., granules, caryopses, and cobs). For example, remnant granules larger than $\sim 20 \mu \mathrm{m}$ would most likely have been produced with ample access to water.

The implications for interpretation of archaeological and paleoenvironmental records are obvious. Water stress in maize results in fewer cobs, fewer kernels per cob, and generally smaller kernels. In arid and semi-arid regions, especially those with marked interannual variation in growing season precipitation, large granules ( $>20 \mathrm{um}$ ) could potentially indicate access to ample water. This is important because irrigation may be very difficult to identify in the archaeological record due to its inconspicuous and ephemeral material consequences. Moisture during the growing season is essential and often the most important constraint on the quantity and quality of an agricultural harvest. Less moisture during the early stages limits the growth and development of both the shoot and root systems (Benson et al. 2013; Boomgarden et al. 2019; Muenchrath 1995; Shaw 1988). Chronic moisture deficits during reproductive stages (silking, tasseling, and kernel filling) produce essentially infertile plants and, therefore, a meager harvest. Our research shows that water stress also affects the size and morphology of starch granules within maize kernels, even if the adult plant survives to maturity. Starch granule size is, therefore, a potentially important environmental and archaeological proxy because it can evaluate the relative performance of prehistoric farming in a specific place and time and it can serve as another piece of evidence in understanding the role of irrigation in the past.

\section{Acknowledgments}

The authors wish to thank the following individuals and organizations. Duncan Metcalfe for his review of the manuscript. Corinne Springer, Joel and Folsom Boomgarden, and the students of the Range Creek Archaeological and Paleoenvironmental Field Schools for access to plant materials from the experiential farm project. We are grateful for Bruce Pavlik's advice on experimental design and editorial comments on the manuscript. We would also like to thank two anonymous reviewers and our colleagues at the University of Utah Archaeological Center (UUAC) for providing helpful suggestions. Any errors or omissions remain the responsibility of the authors.

\section{Declarations}

Permissions: None declared.

Sources of funding: Funding for this research was provided by the Range Creek Field Station, Natural History Museum of Utah.

Conflicts of Interest: None declared.

\section{References Cited}

Adams, K. R. 2015. The Archaeology and Agronomy of Ancient Maize (Zea Mays L.). In Traditional Arid Land Agriculture: Understanding the Past for the Future, edited by S. Ingram and R. Hunt, pp. 15-53. University of Arizona Press, Tucson, AZ.

Adams, K. R., D. A. Muenchrath, and D. M. Schwindt. 1999. Moisture Effects on the Morphology of Ears, Cobs and Kernels of a Southwestern U.S. Maize (Zea mays L.) Cultivar, and Implications for the Interpretation of Archaeological Maize. Journal of Archaeological Science 26:483-496. DOI:10.1006/jasc.1998.0320.

Adams, K., C. A. Meegan, S. G. Ortman, R. E. Howell, L. C. Werth, D. A. Muenchrath, M. K. O'Neill, and C. A. Gardner. 2006. MAIS Maize of American Indigenous Societies) Southwest: Ear Descriptions and Traits that Distinguish 27 Morphologically distinct Groups of 123 Historic USDA Maize (Zea mays L. spp. Mays) Accessions and Data Relevant to Archaeological Subsistence Models. New Mexico Experimental Grow Out, Farmington, NM.

Arbolino, R. 2001. Agricultural Strategies and Labor Organization: An Ethnohistoric Approach to the Study of Prehistoric Farming Systems in the Taos Area of Northern New Mexico. Doctoral 
Dissertation, Department of Anthropology, Southern Methodist University, Dallas, TX.

Benson, L. 2010. Factors Controlling Pre-Columbian and Early Historic Maize Productivity in the American Southwest, Part 1: The Southern Colorado Plateau and Rio Grande Regions. Journal of Archaeological Method and Theory 18:1-60. DOI:10.1007/s10816-010-9082-z.

Benson, L. V., D. K. Ramsey, D. W. Stahle, and K. L. Peterson. 2013. Some Thoughts on the Factors that Controlled Prehistoric Maize Production in the American Southwest with Application to Southwestern Colorado. Journal of Archaeological Science 40:2869-2880. DOI:10.1016/ j.jas.2013.03.013.

Bertoft, E. 2017. Understanding Starch Structure: Recent Progress. Agronomy 7:56 DOI:10.3390/ agronomy 7030056.

Boomgarden, S. A. 2015. Experimental Maize Farming in Range Creek Canyon, Utah. Doctoral Dissertation, Department of Anthropology, University of Utah, Salt Lake City, UT.

Boomgarden, S. A., D. Metcalfe, and C. Springer. 2014. Prehistoric Archaeology in Range Creek Canyon, Utah: A Summary of Activities of the Range Creek Field Station. Utah Archaeology 27:9-32.

Boomgarden, S. A., D. Metcalfe, and E. Simons. 2019. An Optimal Irrigation Model: Theory, Experimental Results, and Implications for Future Research. American Antiquity 84:252-273. DOI:10.1017/aaq.2018.90.

Castetter, E., and W. H. Bell. 1942. Pima and Papago Indian Agriculture. University of New Mexico Press, Albuquerque, NM.

Coltrain, J. 2011. Evidence for Fremont Maize Farming in the Soil Organic Chemistry of Range Creek Canyon. Paper presented at the $76^{\text {th }}$ Annual Meetings of the Society of American Archaeology, Sacramento, CA. Available at: https:// documents.saa.org/container/docs/default-source/ doc-annualmeeting/annualmeeting/abstract/ abstract_2011.pdf?sfvrsn=7b2c1788_4. Accessed on October 20, 2020.

Doolittle, W. E. 1984. Agricultural Change as an Incremental Process. Annals of the Association of American Geographers 74:124-137.
Herzog, N., L. Louderback, and B. Pavlik. 2018. Effects of Cultivation on Tuber and Starch Granule Morphometrics of Solanum jamesii and Implications for Interpretation of the Archaeological Record. Journal of Archaeological Science 98:1-6. DOI:10.1016/ j.jas.2018.07.014.

Holst, I., J. E. Moreno, and D. R. Piperno. 2007. Identification of Teosinte, Maize, and Tripsacum in Mesoamerica by Using Pollen, Starch Grains, and Phytoliths. Proceedings of the National Academy of Sciences 105:5006-5011. DOI:10.1073/ pnas.0800894105.

ICSN. 2011. The International Code of Starch Nomenclature. Available at: http:// www.fossilfarm.org/ICSN/Code.html. Accessed on September 20, 2019.

Ingram, S. E., and R. C. Hunt, eds. 2015. Traditional Arid Lands Agriculture Understanding the Past for the Future. University of Arizona Press, Tucson, AZ.

Jane, J., T. Kasemsuwan, S. Lees, H. Zobel, and J. F. Robyt. 1994. Anthology of Starch Granule Morphology by Scanning Electron Microscopy. Starch 46:121-129. DOI:10.1002/star.19940460402.

Lui, L., S. Ma, and J. Cui. 2014. Identification of Starch Granules Using a Two-Step Identification Method. Journal of Archaeological Science 52:421-427. DOI:10.1016/j.jas.2014.09.008.

Louderback, L. A., N. M. Herzog, and B. M. Pavlik. 2016. A New Approach for Identifying Starch Granules of Wild Plants from Arid Western North America. Starch/Starke 68:1-7. DOI:10.1073/ pnas.1705540114.

Mabry, J. 2005. Diversity in Early Southwest Farming and Optimization Models to Transition to Agriculture. In Subsistence and Resource Use Strategies in Early Agricultural Communities in Southern Arizona, edited by M.W. Diehl, pp. 113-154. Anthropological Papers 34. Center for Desert Archaeology, Tucson, AZ.

Messner, T. C., R. Dickau, and J. Harbison. 2008. Starch Grain Analysis: Methodology and Applications in the Northeast. In Current Northeast Paleoethnobotany II, edited by J. P. Hart, pp. 111-127. New York State Education Department, Albany, NY. 
Metcalfe, D. 2008. Range Creek Canyon. In The Great Basin: People and Place in Ancient Times, edited by C. F. Fowler and D. D. Fowler, pp. 117-123. School for Advanced Research Press, Santa Fe, NM.

Metcalfe, D., and L. V. Larrabee. 1985. Fremont Irrigation: Evidence from Gooseberry Valley, Central Utah. Journal of California and Great Basin Anthropology 7:244-254.

Muenchrath, D. A. 1995 Productivity, Morphology, Phenology, and Physiology of a Desert-Adapted Native American Maize (Zea mays L.) Cultivar. Doctoral Dissertation, Department of Agronomy, Iowa State University, Ames, IA. Available from Retrospective Theses and Dissertations (paper 10967).

Musaubach, M. G., A. Plos, and M. del Pilar Babot. 2013. Differentiation of Archaeological Maize (Zea mays L.) from Native Wild Grasses Based on Starch Grain Morphology. Cases from Central Pampas of Argentina. Journal of Archaeological Science 40:11861193. DOI:10.1016/j.jas2012.09.026.

Nabhan, G. 1983. Papago Fields: Arid Lands Ethnobotany and Agricultural Ecology. Doctoral Dissertation. University of Arizona, Tucson, AZ.

Piperno, D. R., E. Weiss, I. Holst, and D. Nadel. 2004. Processing of Wild Cereal Grains in the Upper Paleolithic Revealed by Starch Grain Analysis. Nature 430:670-673. DOI:10.1038/ nature 02734 .

Piperno, D. R., A. J. Ranere, I. Holst, J. Iriarte, and R. Dickau. 2009. Starch Grain and Phytolith Evidence for Early Ninth Millennium B.P. Maize from the Central Balsas River Valley, Mexico. Proceedings of the National Academy of Sciences 106:5019-5024. DOI:10.1073/pnas.0812525106.

R Core Team. 2019. R: A Language and Environment for Statistical Computing [web page]. Vienna, Austria. Available at: https://www.r-project.org/. Accessed on March 17, 2020.

Reichert, E. T. 1913. The Differentiation and Specificity of Starches in Relation to Genera, Species, Etc.: Stereochemistry Applied to Protoplasmic Processes and Products, and as a Strictly Scientific Basis for the Classification of Plants and Animals. Carnegie Institution of Washington, Washington, DC.
Rhode, D. 1995. Estimating Agricultural Carrying Capacity in the Zuni Region, West-Central New Mexico: A Water Allocation Model. In Soil, Water, Biology and Belief in Prebistoric and Traditional Southwestern Agriculture, edited by H. W. Toll, pp.85100. New Mexico Archaeology Council, Albuquerque, NM.

Shaw, R. H. 1988. Climate Requirement. In Corn and Corn Improvement, $3^{\text {rd }}$ edition, edited by G. F. Sprague and J. W. Dudley, pp. 609-638. American Society of Agronomy, Madison, WI.

Simms, S. R., T. M. Rittenour, C. Kuehn, and M. B. Cannon. 2020. Prehistoric Irrigation in Central Utah: Chronology, Agricultural Economics, and Implications. American Antiquity 85:452-469. DOI:10.1017/ aaq.2020.25.

Talbot, R. K., and L. D. Richens. 1996. Steinaker Gap: An Early Fremont Farmstead. Museum of Peoples and Cultures Occasional Papers 2, Brigham Young University, Provo, UT.

Torrence, R., and H. Barton, eds. 2016. Ancient Starch Research, 2nd edition. Routledge Press, New York City, NY.

Towner, R. H., M. W. Salzer, J. A. Parks, and K. R. Barlow. 2009. Assessing the Importance of Past Human Behavior in Dendrochronological Research: Examples from Range Creek Canyon, Utah. TreeRing Research 65:117-27. DOI:10.3959/2008-4.1.

Wells, J. C. K., and J. T. Stock. 2020. Life History Transitions at the Origins of Agriculture: A Model for Understanding How Niche Construction Impacts Human Growth, Demography and Health. Frontiers in Endocrinology 11:325. DOI:10.3389/ fendo.2020.00325.

Werth, L. C. 2007. Characterization and Classification of Native American Maize Landraces from the Southwestern United States. Agronomy, Iowa State University, Ames, Iowa. Available at: https// lib.dr.iastate.edu/rtd/14628. Accessed on October 14, 2020.

Wrangham, R. W., G. Laden, J. H. Jones, D. Pilbeam, and N. C. Conklin-Brittian. 1999. The Raw and the Stolen: Cooking and the Ecology of Human Origins. Current Anthropology 40:567-594. DOI:10.1086/300083. 
Yang, X., and L. Perry. 2013. Identification of Ancient Starch Grains from the Tribe Triticeae in the North China Plain. Journal of Archaeological Science 40:3170-3177. DOI:10.1016/j.jas.2013.04.004.
Zarillo, S., D. M. Pearsall, J. S. Raymond, M. Tisdale, D. J. Quon. 2008. Directly Dates Starch Residues Document Early Formative Maize (Zea mays L.) in Tropical Ecuador. Proceedings of the National Academy of Sciences 105:5006-5011. DOI:10.1073/ pnas.0800894105. 